\title{
Prevalence of Chagas' Disease in Mulungu do Morro Northeastern Brazil
}

\author{
Roque Aras, Marielza Veiga, Irênio Gomes, Gildo Mota, Bernardo Rodrigues, Rosângela Rabelo, \\ Carmen Guzman-Bracho, Ailton Melo \\ Salvador, BA - Mexico, Mexico
}

\begin{abstract}
Objective - The aim of this paper is to describe the prevalence of T. Cruzi infection in patients of from Mulungu do Morro, a rural tropical region of Northeastern Brazil.

Methods - A cross-sectional study was performed. After randomly selecting samples of the population, and obtaining their consents, patients completed pretested epidemiological and clinical questionnaires. Serum samples from all patients were collected and screened for the presence of T. cruzi antibodies.
\end{abstract}

Results - Of 694 patients examined, 174 patients (25.1\%) tested had a positive serology for Chagas' disease. Of the study population, 341 patients were male with $27 \%$ Chagas' disease prevalence, without a statistical difference. Illiteracy was the only variable related to T. cruzi infection in our population.

Conclusion - In conclusion, our study points to the high prevalence of Chagas' disease among patients in Mulungu do Morro, suggesting that this region has a high frequency of infection and probably active vectorial transmission.

Key-words: Chagas' disease, prevalence, trypanosomiasis

Universidade Federal da Bahia, Secretaria de Saúde do Estado da Bahia, Brasil Instituto Nacional de Diagnostico y Referencia Epidemiologicos, México Mailing address: Roque Aras - Av. Juracy Magalhães Jr, 2426 - S/104 - 41940-060 Salvador, BA - E-mail: roque.aras@uol.com.br
Chagas' disease is an endemic infirmity in Latin America. According to the World Health Organization, this disease infects 16 to 18 million people in South America, with another 90 million at risk of becoming infected, and is responsible for 50,000 deaths each year. In Brazil, according to the Ministry of Health's data, a $4.22 \%$ prevalence exists, which corresponds to 6 million cases. The infection can remain asymptomatic, that is in an indefinite form, or as in $30 \%$ of cases, it manifests itself by compromising the heart, causing heart dilation, severe arrhythmias, and sudden death. About $10 \%$ of patients develop a digestive form that involves the esophagus and the large intestine ${ }^{1-5}$.

The Mulungu do Morro municipality is located in an endemic region to infectious parasitic diseases, such as neurocysticercosis and Chagas' disease. During an earlier study carried out among patients who had suffered loss of consciousness, we found positive serology for T. cruzi infection in $44.5 \%$ of the cases; $55.6 \%$ of individuals with syncope had Chagas' disease. We also observed that some of the patients were in the below-20 age group, which could suggest the possibility of active vectorial or vertical transmission $^{7-9}$. The objective of this study is to determine the prevalence of positive serology for T. cruzi infection in the Mulungu do Morro municipality.

\section{Methods}

The town of Mulungu do Morro is located in a poor region in the western part of the state of Bahia, $460 \mathrm{~km}$ away from its capital Salvador, with an area of $518 \mathrm{~km}^{2}$. According to demographic data provided by IBGE (1991), it has an estimated population of 15,000 inhabitants. Its economy is mainly based on the cultivation of beans, coffee, castor bean, sisal-hemp, and corn.

Considering that according to the 1995 Municipal Prefecture's census, the municipality has a population of 15,085 inhabitants and taking into account an expected $5.44 \%$ prevalence among the population of Chagas' disease for the state of Bahia, one estimates a $3-10 \%$ variation of prevalence and a $95 \%$ level of confidence. So, we performed 
a cross-sectional study of 800 individuals, which corresponds approximately to 5 persons per household or the equivalent to 160 homes, chosen through a random drawing.

During the period from March 1998 through June 1999 and after obtaining patient consent, the patients completed a pretested epidemiological and clinical questionnaire. After contacting the sanitation authorities and local leaders, we initiated a serological survey among randomly chosen patients. The members of the medical team, accompanied by Community Health Agents, attended the study patients at the project's ambulatory clinic or at their homes. At the time of the patients' arrival, a clinical- epidemiological chart was filled out and a blood sample was collected for serology. The epidemiological questionnaire elicited information pertaining to demographic and socioeconomic variables. Serum samples from all the patients were collected and screened for the presence of T. cruzi antibodies by using ELISA and hemoagglutination. Samples showing different profiles were considered indeterminate and tested by indirect immuno-fluorescence. Samples were considered positive when antibodies were present in 2 tests.

Descriptive statistics has been used to analyze the variables and their distribution within the study population. In addition to comparing the encountered prevalence with that reported in the literature, averages, proportions, and descriptions of demographic findings were calculated. The results found were evaluated through measures of association. It was considered significant a $\mathrm{p}<0.05$.

\section{Results}

During the period from March 1998 thru June 1999, 694 patients were evaluated. The prevalence of positive serology for T. cruzi infection was $25.1 \%$ (174 patients) of the study population sample. Considering distribution by sex, we observed that $341(50.3 \%)$ were male with a prevalence of positive serology for infection by $T$. cruzi of $27 \%$ (fig. 1 ). In relation to sex and age, the incidence of positive serology did not demonstrate a statistically significant difference.

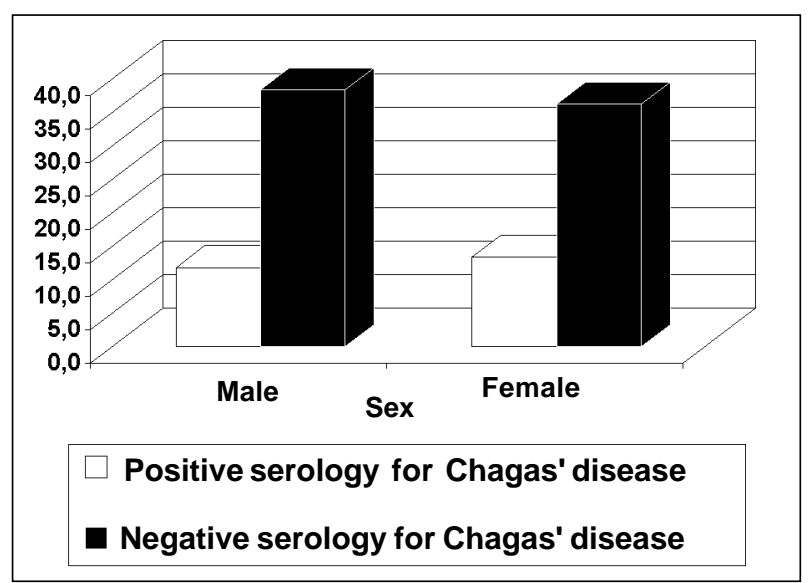

Fig. 1 - Distribution of study population by sex and positive serology for Chagas' disease.
When analyzing the frequency of positive serology by age group, we found a progressive distribution and a growth of positive examinations occurring up to the age of 60 . We have also observed the significant involvement of children, who are younger than 7 years old $(3.3 \%)$, of school age $(5.3 \%)$, and of individuals within the 15 to 30 year age group $(26.5 \%)$. This distribution by age group and the respective prevalence of $T$. cruzi is demonstrated on figure 2 . When a comparison was made by age groups, we found statistical significance $(\mathrm{p}<0.001)$.

While analyzing the relationship between those with positive serology for Chagas' disease and their places of residence and taking under consideration the variable residency, those residing in rural areas $(26.4 \%)$ versus those from urban areas $(21.8 \%)$, no difference was found.

When comparing the educational variable (illiteracy, primary, secondary, and college education) with the prevalence of positive serology for infection by $T$. cruzi, a significant difference was observed between those with a higher level of education and all other levels $(p<0.004)$ (fig. 3). Figure 4 demonstrates the distribution by levels of education and their respective prevalence.

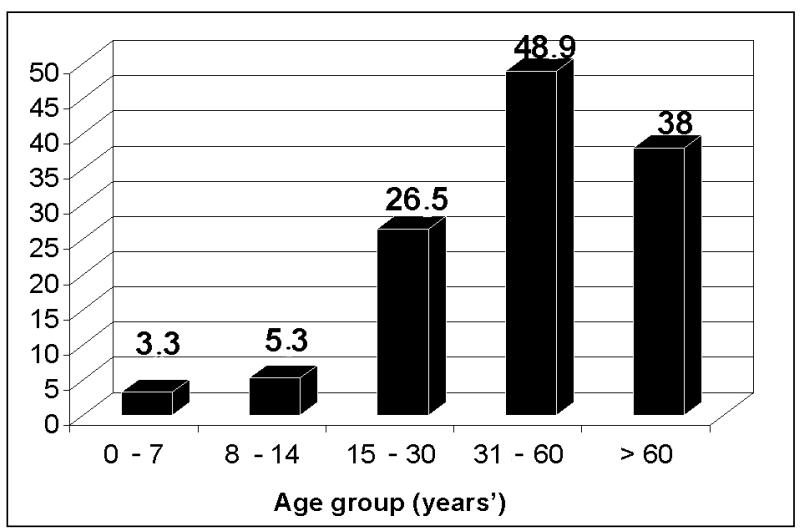

Fig. 2 - Prevalence of infection by T. Cruzi and distribution by age groups.

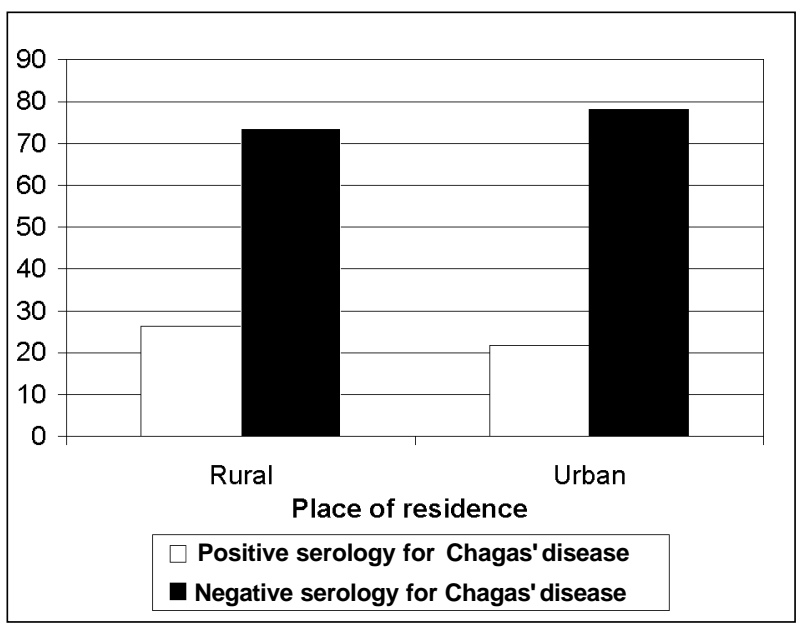

Fig. 3 - Population distribution according to positive serology for Chagas' disease and place of residence. 


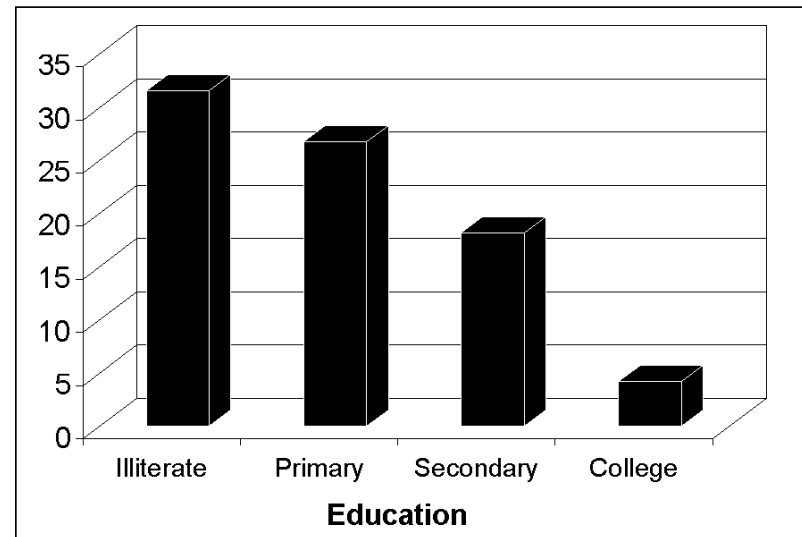

Fig. 4 - Distribution of population sample according to positive serology for Chagas' disease and level of education.

\section{Discussion}

Chagas' disease continues to be one of the main endemic diseases in Brazil. Even though the government during the last decades has adopted many policies, one still finds isolated, active focal areas of this disease with vectorial transmission. Measures for eradication of Chagas' disease through the elimination of Triatominae, vectors of this disease, through the use of insecticides have obtained great success; however, this result was diminished due to the continued poor habitation and sanitation conditions and poverty of the population ${ }^{4,9-11}$.

The high prevalence of positive serology for Chagas' disease found in the Mulungu do Morro municipality
(25.1\%) is opposed to the national levels (4.22\%) and those of the state of Bahia (5.44\%). Although the Ministry of Health believes that vectorial transmission is under control in most of the country, they admit that the states of Bahia and Tocantins are still centers of active infection ${ }^{6-8,10,12}$.

Among the student population within the 7 to 14 year olds, the national prevalence varies from $0.14 \%$ to $0.28 \%$, while in the state of Bahia a serological survey made during the period from 1997 to 1999, by FNS/SESAB, showed a rate of $0.04 \%$. By comparison, the $5.3 \%$ student infection rate from Mulungu do Morro is 5 times that of the national infection average. These rates demonstrate such diverse differences that they may be reflecting an underestimation of the problem in our State ${ }^{6-8}$.

We conclude that the Mulungu do Morro municipality has a high prevalence of infection by T. cruzi. This high prevalence is associated with the population's low level of education. We have not succeeded in associating the area of residence with serum positivity, due to the fact that the urban population in the municipality also has rural activities. Our data suggest that due to the high rate of infection found in the group of those below the age of 5, active vectorial transmission is occurring in the municipality, making it mandatory for sanitation authorities to take adequate measures for the control of this endemic disease.

\section{Acknowledgments}

Secretary of Health, Municipal Prefecture, and to Mulungu do Morro's Community Health Agents. Supported by:CADCT/SEPLANTEC

\section{References}

1. Organização Mundial da Saúde. Control de la Enfermidad de Chagas: série de informes técnicos-811, 1991.

2. Organización Panamericana de la Salud. Las Condiciones de Salud en las Américas. Pub Cient 1990; 1: 524.

3. Hayes RJ, Schofield CY. Estimacion de las tasas de incidência de infecciones y parasitarias crônicas a partir de la prevalência: La Enfermidad de Chagas en América Latina. Bol of Sanit Panan 1990; 108: 308-16.

4. Ministério da Saúde/Fundação Nacional de Saúde. Controle da Doença de Chagas. Diretrizes Técnicas. Brasília, 1994.

5. Brener Z, Andrade Z. Trypanosoma Cruzi e Doença de Chagas. Guanabara Koogan: Rio de Janeiro,1979.

6. Edgar Merchán-Hermann. Informe Epidemiológico do SUS. Diagnóstico macrorregional das situações das endemias das regiões Norte e Nordeste. V1(3), $\mathrm{jul} / \mathrm{set}, 1997$.
7. Informe da SESAB/FNS. Inquérito sorológico em escolares para doença de Chagas no estado da Bahia, 1999. Informe preliminar.

8. Camargo ME. Inquérito sorológico da prevalência de infecção chagásica no Brasil, 1975/1980. Rev Inst Med Trop São Paulo 1984; 26: 192-236.

9. Aras R, Veiga M, Gomes I, Rabelo R, Guzman C, Melo A. Prevalence of Chagas' disease in patients with loss of conscience in Mulungu do Morro, Northeastern Brazil (encaminhado para publicação).

10. Ministry of Health, Brasilia. Report to the IX Intergovernment Comission, Rio de Janeiro, March 2000: 48-74.

11. Dias JCP. Epidemiologia. Trypanosoma cruzi e Doença de Chagas. Ed. $2^{a}$. Edição Brener/Andrade/Barral-Neto. Rio de Janeiro: Guanabara Koogan, 2000.

12. Schmunis GA. Trypanosomiasis as a Public Health Problem. Pan American Health Organization, 1994; 547: 3-29. 